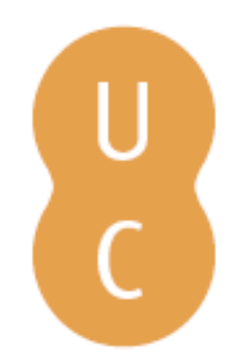

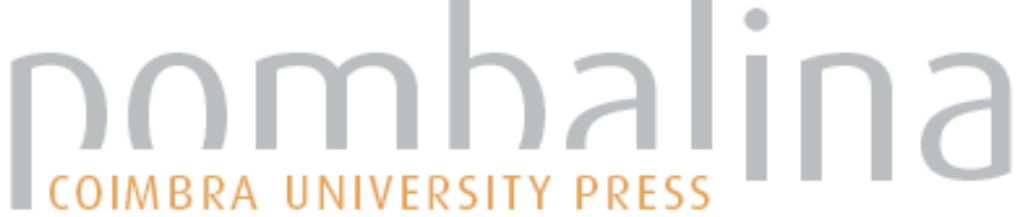

\section{Territórios emergentes vs. territórios administrativos: conflito e cooperação para a evolução das culturas de planeamento}

Autor(es): Queirós, Margarida

Publicado por: Imprensa da Universidade de Coimbra

URL

persistente: URI:http://hdl.handle.net/10316.2/30834

DOI: $\quad$ DOI:http://dx.doi.org/10.14195/978-989-26-0244-8_48

Accessed : $\quad$ 26-Apr-2023 00:56:53

A navegação consulta e descarregamento dos títulos inseridos nas Bibliotecas Digitais UC Digitalis, UC Pombalina e UC Impactum, pressupõem a aceitação plena e sem reservas dos Termos e Condições de Uso destas Bibliotecas Digitais, disponíveis em https://digitalis.uc.pt/pt-pt/termos.

Conforme exposto nos referidos Termos e Condições de Uso, o descarregamento de títulos de acesso restrito requer uma licença válida de autorização devendo o utilizador aceder ao(s) documento(s) a partir de um endereço de IP da instituição detentora da supramencionada licença.

Ao utilizador é apenas permitido o descarregamento para uso pessoal, pelo que o emprego do(s) título(s) descarregado(s) para outro fim, designadamente comercial, carece de autorização do respetivo autor ou editor da obra.

Na medida em que todas as obras da UC Digitalis se encontram protegidas pelo Código do Direito de Autor e Direitos Conexos e demais legislação aplicável, toda a cópia, parcial ou total, deste documento, nos casos em que é legalmente admitida, deverá conter ou fazer-se acompanhar por este aviso.

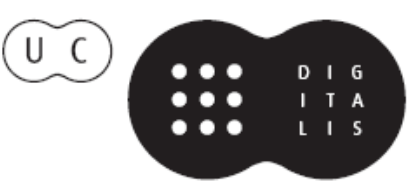




\section{TRUNFOS DE UMA}

\section{EOGRAFIA ACIVA}

\section{DESENVOLVIMENTO LOCAL,}

AMBIENTE,

ORDENAMENTO

E TECNOLOGIA

Norberto Santos

Lúcio Cunha

COORDENAÇÃO 
Margarida Queirós

Instituto de Geografia e Ordenamento do Território e Centro de Estudos Geográficos

Universidade de Lisboa (IGOT-UL / CEG-UL)

\section{TERRITÓRIOS EMERGENTES VS. TERRITÓRIOS ADMINISTRATIVOS: CONFLITO E COOPERAÇÃO PARA A EVOLUÇÃO DAS CULTURAS DE PLANEAMENTO}

\section{INTRODUÇÃO}

A mera formulação de um problema é no minimo muito mais essencial do que a sua solução que, quem sabe, será um assunto simples de destreza experimental...Formular novas questöes, olhar para velhos problemas de um novo enfoque será muito mais criativo e marca avanços importantes na ciência.

Einstein, 1921

O século XXI modificará muitas das nossas assunções básicas sobre o planeamento territorial. Para Xavier Comtesse os territórios definidos pelos governos desconectaram-se dos sistemas de relação dos cidadãos e das instituiçôes que neles operam. Novas formas de interagir possibilitadas pelas TIC criaram uma "camada" adicional, que se projecta sobre os territórios administrativos, e simultaneamente estimularam uma cultura de participaçáo que não raras as vezes colide com práticas e procedimentos tradicionais da administração dos territórios. Em resultado, os governos são obrigados a repensar os seus processos, incluir a participação e aprender a gerir a colaboração entre múltiplos actores dos sectores público e privado (Comtesse, 2008).

Mais do que desregulação, esta situação exige uma redefinição do papel das instituiçóes da administração pública e da sua cultura de planeamento. A tarefa é política no seu core e a cooperaçáo um meio que faculta o objectivo do desenvolvimento; por esse motivo Ostrom (1990) e Sachs (2008) sustentam que a actividade humana é organizada por instituiçôes que facilitam a cooperação a longo prazo, começando pelo cidadão e acabando nos governos.

O desafio da cooperação não é novo, do nível micro ao global. Problemas sociais complexos têm múltiplos actores, constituindo simultaneamente parte do problema e da solução. Conseguir a cooperação entre actores díspares é o desafio mais duro de todos (Sachs, 2008). Mas nem sempre se pensou assim. Com efeito, a antiga história que mudou o rumo da ciência no séc. XIX contada através da biologia evolucionista sobre a existência das espécies na Terra (a árvore da vida), e que assimilamos durante muitos anos, relata uma cronologia de seres vivos que, lutando e competindo, seriam os sobreviventes, os 'eleitos' da vida, através do mecanismo da selecção natural. Ora o passado e o presente fundem-se hoje numa narrativa sobre a existência dos seres vivos que não se associa apenas à selecção natural como a única força para a mudança evolutiva, ou seja, à noção de 
competição a partir da qual o mais forte sobrevive. Muitos trabalhos têm sido dedicados à natureza cooperativa da vida na Terra, mostrando que diversos modos de cooperação são responsáveis por novas formas de evolução. A cooperação, a acção colectiva, a comunicação e a interdependência ocupam hoje um papel central na investigaçáo e este assunto tornou-se transversal a uma série de disciplinas.

Muito do pensamento e práticas do planeamento nos últimos 25 anos na Europa modificou-se: de uma visão estritamente associada ao território físico, onde se procuravam as qualidades dos lugares e a sua conectividade, para o reconhecimento da importância das questóes socioeconómicas e ambientais na prossecuçáo do desenvolvimento (Healey, 2007). Esta mudança de perspectiva fez-se acompanhar de um pensamento crítico, da crescente percepção de que os territórios não podem ser planeados de uma forma linear - da intenção de planear, à acção e resultados como delineado. Cada vez mais se assiste a uma dinâmica complexa de múltiplos nós e redes de relação que se intersectam, cada qual com a sua dinâmica, história e geografia, às quais se coligam uma panóplia de novos actores que actuam através de relaçóes não-lineares (usando a internet). Esta complexidade desafia os actores e as instituiçóes do planeamento territorial a repensar pressupostos tradicionais e a refazer sistemas e modos de planear o território, integrador, inclusivo, sustentável e espacial (Davoudi e Strange, 2009).

A partir da 'perspectiva evolucionista' este artigo convida a uma reflexão sobre o paradigma do planeamento territorial colectivo, participado e cooperativo de onde emergem conceitos, valores e procedimentos que rompem com o status quo relativo à tradiçáo do planeamento. Afinal a explicação da cooperação é central no estudo do comportamento animal e em sociedades humanas comprova-se que (i) a cooperação é fundamental à vida e (ii) os indivíduos actuam colectivamente (densidade de relaçóes) já que são interdependentes e daí colhem vantagens para a sobrevivência nos territórios. A novas formas de comunicação (TIC), enfatizaram a emergência da cultura de colaboração e de participação na 'produçáo' dos territórios e 'empurram' os governos para novas formas de gestão dos processos de planeamento, numa abordagem relacional.

\section{ACÇÃO COLECTIVA}

... It's a dog-eat-dog world out there. But is that really so? Is brute competition the sole evolutionary driver in the animal world - and by extension, our own - or do cooperation and collaboration play a significant role?

Geoff Olson em http://commonground.ca/iss/0509170/cg170_geoff.shtml

O poder explicativo e preditivo da teoria evolucionista converteu-se no princípio organizador central da biologia moderna, direccionando a investigaçáo e providenciando uma explicação unificadora para a diversidade da vida na Terra. Desde Charles Darwin e Alfred Russel Wallace, a teoria da evoluçáo por selecção natural tornou-se uma referência científica do domínio público - aí encontrou o seu maior apoio. Na sua publicação mais decisiva, On the Origin of Species by Means of Natural Selection, em 1859, Darwin menciona duas formas de luta, a primeira que opóe organismo contra organismo numa luta por recursos limitados, e a segunda, o organismo contra o ambiente, uma luta que conduz à cooperaçáo entre organismos. Thomas Henry Huxley, um evolucionista fervoroso, em The Struggle for Existence in 
Human Society, publicado em 1894, enfatiza o primeiro aspecto competitivo, em que os organismos lutam ferozmente uns contra os outros. Mais tarde os "darwinistas sociais" influenciados por esta visão aplicam-na à sociedade humana (Ostrom, 1990; Ruse, 2002).

Segundo Stephen Jay Gould (1991; 1997), o critério da selecção natural ou o sucesso reprodutivo funciona de muitas maneiras: a vitória numa batalha pode ser um caminho, mas a cooperação, simbiose e ajuda mútua podem igualmente assegurar o sucesso. Darwin reconhece uma função para a cooperação, tanto quanto para a competição. Numa famosa passagem em Origin of Species (1859: 62, cit. Ruse, 2002), Darwin explica o seu conceito de luta evolutiva em linguagem metafórica: I use this term in a large and metaphorical sense including dependence of one being on another, and including (which is more important) not only the life of the individual, but success in leaving progeny (...) I use for convenience sake the general term of struggle for existence.

Em muitas circunstâncias, a cooperação e a ajuda mútua são os resultados mais comuns da luta pela existência, pelo menos assim pensava Peter Kropotkin no início do séc. XX ao escrever Mutual Aid, a Factor in Evolution. As suas ideias sobre a natureza cooperativa da vida têm sido recuperadas, sobretudo nos últimos 30 anos. Na essência do seu pensamento, a alavanca da evolução encontra-se na cooperação entre espécies com a finalidade de maximizar a sobrevivência em condiçóes ambientais extremas, ou seja, quando as circunstâncias hostis pressionam uma comunidade, surgem fortes laços de cooperação (Kropotkin, 1902).

Nem todas as interacçóes entre espécies envolvem conflito: a luta ocorre de muitas formas e algumas delas conduzem à cooperação entre membros de uma espécie, como a melhor forma de retirar vantagens individuais, ou seja, há interacção com benefícios mútuos para evoluir entre grupos de organismos (http://www.marxists.org/subject/science/essays/ /kropotkin.htm). Há hoje evidências científicas suficientes que suportam o argumento básico de Kropotkin (por exemplo, os estudos em torno das colónias da bactéria Pseudomonas (http://wellcometreeoflife.blogspot.com/2009/09/evolution-of-cooperation.html).

Martin Nowak (2006) afirma que a cooperação é necessária à evolução para construir novos níveis de organização e associa a cooperação ao 'terceiro pilar da evolução' depois da mutação e da selecção natural, e muitos outros cientistas têm procurado aprofundar o conhecimento sobre as forças que levam à acção colectiva e às diversas formas de cooperação (laços de parentesco, altruísmo recíproco...). Assumimos claramente este pressuposto, já que entendemos a perspectiva evolucionista uma base ampla e sólida para compreender os processos que conduzem à evolução na esfera das ciências sociais.

O diálogo interactivo relativo a estratégias de cooperação em grupos, a suposição, comunicação, deliberação e cooperação desempenham um papel de extrema relevância na espécie humana e estão na base da evolução social (Hodgson, 2008). E se assim não fosse, como explicaríamos o sucesso da civilização humana, desde os grupos familiares, tribos, comunidades, à organização em sociedade?

Com efeito, desde a utilizaçáo de técnicas rudimentares de grupo para a sobrevivência, às sofisticadas tecnologias de informação e comunicação usadas para o lazer, observa-se um aumento de riqueza e uma progressiva melhoria da organizaçáo social. Desde os tempos das civilizaçóes da agricultura que algumas formas de acção colectiva para resolver problemas trouxeram maior informação, possibilitaram a organização cultural e a acumulação de riqueza. A comunicação desempenhou um papel fundamental na cooperação, desde a invenção do alfabeto, passando pela imprensa e hoje a internet, assim como os mecanismos de 
troca, como as feiras e os mercados ao longo das rotas da civilização, até à banca e às seguradoras, ícones do capitalismo, constituem invençóes que permitiram e desenvolveram a acçáo colectiva. Rheingold (2002) explica-nos que muito recentemente as tecnologias de informação e comunicação trouxeram até cada um de nós um desktop, ou seja, possibilidades infinitas de absorção, transmissão e de audiência, às quais se juntam uma máquina de impressão e um telefone, um mercado e uma comunidade - antevendo um brutal incremento de poder de informação e comunicação e de acçáo colectiva no futuro, dado o aumento exponencial da capacidade de interagir cooperativamente.

As ideias darwinistas de herança, variação, selecção e cooperação ajudam a compreender os mecanismos que criam e sustentam a preservação e transmissão de informação, muito úteis inclusive para a discussão acerca da cooperação em sociedade humanas (Hodgson, 2008). Argumenta-se que a interdependência se relaciona com a cooperação - aconteça o que acontecer, o melhor resultado será sempre a cooperaçáo. Esta ideia foi amplamente divulgada através de um problema da Teoria dos Jogos (Neumann e Morgenstern, 1944), o Dilema do Prisioneiro (DP), formalizado por Albert Tucker. O DP é o exemplo clássico que mostra serem muitas das decisóes tomadas individualmente, apesar de perfeitamente racionais, obstáculos à procura dos ganhos colectivos. Múltiplas decisóes tomadas isoladamente conduzem a maus resultados para todos; havendo alternativas possíveis de compromisso colectivo, o melhor interesse de todos seria salvaguardado ( $c f$. Queirós, 2000).

Robert Axelrod (1985; 1997) estudou uma extensão ao cenário clássico do dilema do prisioneiro e descobriu através da aplicação do DP que as estratégias "olho por olho" (tit for tat) ou "egoístas" (soma nula), tendiam a ser piores, a longo prazo, do que as estratégias "altruístas" (soma positiva). Usou isto para mostrar um mecanismo que explica o que antes tinha sido um ponto crítico na teoria da evolução: como pode evoluir um comportamento altruísta a partir de mecanismos puramente egoístas na selecção natural.

A teoria dos jogos evidencia que a cooperação persiste porque tem resultados positivos individuais e para a sociedade; com efeito, Elinor Ostrom, a primeira mulher que conquistou o Nobel da Economia, em 2009, demonstrou que as bases das nossas transacçóes estão nas nossas organizaçôes/redes sociais e assim co-evoluimos (Ostrom, 1990). Ostrom analisou diferentes modos de governar os 'bens comuns' através de instituiçóes de acção colectiva, contrastando com o dilema social da tragédia dos comuns, de Garrett Hardin (The Tragedy of the Commons, ensaio publicado em 1968 na revista Science) que demonstra que os humanos destruirão inevitavelmente qualquer recurso comum se não houver restriçóes ao seu uso. Recorrendo ao estudo de casos de partilha de água, florestas e pescas, Ostrom comprova que os problemas de utilização de bens comuns podem ser resolvidos por organizaçóes voluntárias vocacionadas para a acção colectiva, através das quais as pessoas escapam ao dilema do prisioneiro.

$\mathrm{Na}$ maior parte dos casos, quando as circunstâncias hostis pressionam uma comunidade, animal ou humana, aumentam os laços de cooperaçáo. Num mundo de alta velocidade, de elevada conectividade e de alertas de (in)segurança esta mensagem torna-se particularmente importante. A uma escala global, a cooperação associa-se a um jogo de soma positiva (winwin). Exemplos disto são as ferramentas de software associadas a open sources (código aberto, também conhecido por software livre) e que são alimentadas por redes sociais funcionando segundo modelos colaborativos de partilha de programas: Google, Bit Torrent, Napster, Ebay, Slashdot, Seti@home, Floss, Sourceforge, Think Cicle, Clickworkers. 
Em suma, no passado, por volta do VI milénio a.C. - das primeiras civilizaçôes, da sedentarização da população e da revolução urbana e agrícola - novas formas de comunicação e de cooperação criadas por inovaçóes tecnológicas ajudaram a criar riqueza e impulsionaram o desenvolvimento da sociedade humana. No III milénio d.C., empresas como a IBM, HP, Sun Microsystems ou a NASA, e as universidades (Berkeley, Santa Fé Institute), centros de excelência de inovação tecnológica, e as 'gentes anónimas', estão a partilhar o seu conhecimento por todo o mundo; as estratégias colaborativas destas companhias e de outras similares passam pela difusáo de conhecimento que reverte também no seu próprio interesse - a Google enriquece-se e recria-se através do enriquecimento dos milhares de bloggers (Rheingold, 2002). Do mesmo modo, milhares de 'cidadãos anónimos' disponibilizam os seus desktops para se ligarem em rede na procura de vida extra-terrestre no espaço galáctico, como o faz Seti@home (SETI, acrónimo para search for extra-terrestrial intelligence, um projecto da Universidade da Califórnia, Berkeley). Toda esta dinâmica interactiva e co-evolutiva derivada da partilha tem implicaçóes tremendas e muito variadas, as quais ainda mal aprendemos a conhecer (Rheingold, 2002).

\section{GRUPOS SOCIAIS, TERRITÓRIOS ADMINISTRATIVOS E TERRITÓRIOS EMERGENTES}

Territories as defined by government have become disconnected from the ecosystems in which people and business live and work. New ways of communicating have created an additional layer on top of these territories and ecosystems, ultimately defining new territories in which we have to coexist.

Xavier Comtesse, 2008

Le Galès (2007) e Contesse (2008) definem bem o problema que se levanta com a existência de sistemas sociais que não funcionam de modo articulado com os sistemas territoriais e relacionais em que operam as instituiçóes: do ponto de vista material, por muito tempo, os 'territórios' equivaliam ao mapa administrativo das regióes geográficas. Recentemente multiplicaram-se as instituiçóes e pessoas que operam em territórios que não coincidem com o espaço físico administrativo.

Rheingold (2002) fornece uma perspectiva útil ao entendimento deste desajuste: a sociedade tornou-se mais móvel, interactiva e tem acesso a informação (fenómeno em contínua expansão), um resultado das novas tecnologias de comunicação e de informação, adicionando rapidez e complexidade aos fluxos (de relaçóes económicas e de interacçáo social) que ocorrem no e para além do espaço físico. A sobreposição e vazios gerados nas áreas administrativas e a incapacidade institucional em responder cabalmente sobre o poder de $o$ que e onde se pode fazer, gerou a necessidade de um diálogo com múltiplos actores, ou seja, intensificou os processos participativos.

A internet (um mesmo mecanismo que providencia vídeo, áudio e texto) capacita as pessoas para agir de forma diferente ou mesmo impossível no passado, origina teias de relacionamento melhoradas e amplificadas, fomenta a multiplicação de grupos sociais estruturados em rede, tudo isto sem que se possa identificar uma 'inteligência centralizada' ou um centro de comando e controlo (Johnson, 2001). Porém, estes grupos que partilham interesses estruturam-se em torno de 'centros de gravidade' relacionais, apoiam-se e aprofundam relaçóes de cooperação e laços de pertença (Johnson, 2001; Rheingold, 2002; Contesse, 2008). Por outras palavras, as ferramentas digitais capacitam os sistemas sociais, grupos ou comunidades de relação, dando 
origem a acçóes emergentes colectivas, a movimentos de cidadania e de empreendedorismo social, a actividades de inclusão, políticas, comerciais, de diversão, artísticas, etc., favorecendo literacias de participação e novas formas de riqueza.

Estratégias descentralizadas, auto-organização e acção colectiva evitam as excessivas concentrações de poder, são flexíveis e dão voz ao cidadão comum (Johnson, 2001; Rheingold, 2002). Os melhores exemplos são dados pelas organizaçóes de protestos em todo o mundo associados ao movimento anti-globalização (ex. Seattle em 1991). What emerged on the streets of Seattle and Washington was an activist model that mirrors the organic, interlinked pathways of the Internet (Johnson, 2001: 226). Estas movimentações de conflito divergem consideravelmente dos movimentos de trabalhadores, sindicalistas, anarquistas, partidários, entre outros (cimentados em estruturas tradicionais hierárquicas e aderindo a modelos ou ideais divulgados por líderes), porquanto não estruturados como os sistemas clássicos de representação colectiva, assumem o formato de comunidades de interesses ou de grupos de afinidades com geometrias variáveis, sem um foco ou líder preciso e utilizando os media para difundir imagens fortes e diversificadas, dispersos no espaço e intermitentes no tempo.

O conflito patente nas contestaçóes colectivas associadas à sociedade civil, organizaçóes não governamentais e activistas diversos, representam os 'novos' movimentos sociais espontâneos que reivindicam espaços de cidadania que não se sentem representados pelas entidades existentes; na ausência de interlocutores para a negociaçáo, a cidadania de protesto expressa-se contra o não reconhecimento e apologia dos seus interesses na esfera pública.

As TIC aceleram e constroem mais interacçóes locais e globais, tornam possível novos níveis de cooperação, o que implica uma maior capacidade de mobilização social, sem liderança definida, anónima e espontânea mas cuja alavanca mobilizadora é a cooperação (ex. flash mobs: uma componente digital e outra física).

Onde o mundo físico, material se cruza com o imaterial é ao nível mais básico: na esfera das nossas regiōes, cidades, bairros, ruas, casas (Comtesse, 2008). Daí que se observe, no que respeita às actividades de planeamento, do ordenamento do território e do urbanismo, a emergência de conflitos que opóem os interesses da sociedade civil e dos seus representantes aos 'eleitos'. Com efeito, as entidades da administraçáo pública decidem a localização de equipamentos e infra-estruturas e normas e directrizes que regulam os territórios, que entendem servir melhor as pessoas e as comunidades. Ora neste mundo interactivo, o território surge valorizado como um bem comum, pelo que, as entidades não governamentais e a sociedade civil contestam decisóes da administraçáo, apelando para os valores das culturas populares, da qualidade de vida e da protecção do património e do ambiente, gerando estruturas complexas de relaçóes e sobreposição e vazios na 'coisa pública'.

Os territórios da comunicação ou os territórios emergentes das redes de actores, públicos e privados, surgem frequentemente justapostos aos territórios administrativos, e absorvem um crescente número de participantes. Toda esta evidência revela uma dificuldade acrescida de 'leitura' do território e remete para a importância de conhecer, de mapear estes fenomenos, tarefa só possível através do diálogo cooperativo transdisciplinar. Afinal o que se trata aqui é da crescente percepção de uma tensão entre a cultura da representatividade - que detém a legitimidade democrática das instituiçóes do Estado-nação - e a cultura participativa caracterizada por fóruns multi-actores interactivos, sem mediaçáo formal e extra-parlamentares. Este conflito revela problemas de confiança e de reputação: a desconfiança da sociedade civil perante os sistemas públicos (os árbitros tradicionais do conflito como os parlamentos e tribunais) tomados por ineficientes e assim deslegitimados. 


\section{CONCLUSÃO: NOVAS CULTURAS DE PLANEAMENTO}

\section{(...) intelligent territories that function in a multiscalar way, in order that the relationship between natures, networks and nodes can foment the 'emergence' of an urban intelligence.}

Emergent Territories Group/Institute for Advanced Architecture of Catalonia, 2009

A persistência da cooperaçáo nas sociedades humanas, desde a sua origem às dinâmicas sociais actuais, demonstrou ter construído vantagens evolutivas (Axelrod, 1985, 1997). E a auto-estruturação da organização social, através da mediação de tecnologias, gerou comportamentos inteligentes emergentes (smart mobs segundo Rheingold, 2002). Os biólogos interrogaram-se sobre a 'tragédia dos comuns', os economistas usaram o 'dilema do prisioneiro' para demonstrar estratégias competitivas e cooperativas e, hoje, os analistas das redes sociais diligenciam no sentido de aumentar os níveis e de encontrar novos modos de cooperação possíveis.

Johnson (2001) refere estudos que comprovam comportamentos emergentes em sistemas como os das colónias de formigas, quando os indivíduos no sistema prestam atençáo aos seus vizinhos imediatos em vez de esperarem ordens vindas do topo. Pensam e agem localmente, mas o seu comportamento global produz um sistema global organizado. E este caso refere-se a agentes cuja comunicação se processa por um vocabulário de sinais muito estrito. Transposta para os humanos, esta forma de comunicar e de agir náo tem limites quando potenciada pela convergência dos meios de comunicação como os que já existem hoje à disposição da espécie humana.

O cidadão comum, a 'gente vulgar', interage e coopera mesmo quando não se conhece e tudo isto se tornou possível porque estes actores tiveram ao seu dispor capacidade simultânea de comunicação e de computação. Esta convergência tecnológica multiplicou as nossas possibilidades de intervenção em assuntos para os quais os governos não estavam preparados. Deu origem aos territórios emergentes onde os actores náo tradicionais dos processos de decisão 'jogam em diversos tabuleiros relacionais' estão mais capacitados e interferem sistematicamente e numa base regular.

Os territórios emergentes são incontestavelmente uma oportunidade de reconfiguração da relação de forças das culturas representativa e participativa, incentivando à colaboraçáo e, por conseguinte, a patamares superiores da evolução social. Estes territórios multi-actores e multi-escalares constroem processos descentralizados e participativos, sáo uma oportunidade para recriar alfabetos de planeamento alterando as narrativas dos territórios.

As novas culturas de planeamento assentam, assim, numa abordagem cultural forte. Mais do que nunca, a mediação, a reputação e a confiança entre instituiçôes são elementos-chave na co-criação e co-evolução dos sistemas sociais. Referimo-nos a processos em que o cidadão comum assume um lugar central e exige a presença e a acção de entidades públicas reguladoras confiáveis, saindo reforçado o seu sentimento de pertença aos territórios.

As novas culturas de planeamento constroem-se a partir de várias respostas possíveis (políticas e técnicas) aos problemas e conflitos de interesses, ao reconhecimento das interdependências entre os 'eleitos' e os 'não eleitos', à integração das comunidades de partilha e outras formas associativas nos processos de decisão, à ponderaçáo simultânea que o cidadão comum dá ao 'intangível' e ao pragmatismo das actuaçóes, à exploração das potencialidades das tecnologias de informação e comunicação para a capacitação das pessoas e dos territórios, e aos sistemas de avaliação mais escrutinados e complexos. Nas novas 
culturas de planeamento, o centro da cooperação reside na confiança nas tecnologias e nas instituiçóes colectivas. Esta é uma condição essencial, todavia, o diálogo será forçosamente interdisciplinar. Que formas novas de riqueza serão geradas no futuro se soubermos mais sobre a cooperação?

\section{REFERÊNCIAS BIBLIOGRÁFICAS}

Axelrod, Robert (1985) The Evolution Of Cooperation, USA: Basic Books.

Axelrod, Robert, (1997) The Complexity of Cooperation: Agent-Based Models of Competition and Collaboration, Princeton University Press.

Comtesse, Xavier, (2008) Direct Territories, ThinkStudio www.thinkstudio.com

Davoudi, Simin; Strange, Ian (eds.) (2009) Conceptions of Space and Place in Strategic Spatial Planning, The RTPI Library Series, London: Routedge.

Gould, Stephen J., (1991) Bully for Brontosaurus: Reflections on Natural History, New York: W.W. Norton.

Healey, Patsy, 2007. Urban Complexity and Spatial Strategies. Towards a relational planning for our times, The RTPI Library Series, London: Routedge.

Hodgson, Geoffrey M. (2008) 'Darwinismo e ciências sociais: um diálogo possível'. Estudos Avançados [online], vol.22, nº3: 271-280. ISSN 0103-4014.

Huxley, Thomas Henry, The Struggle for Existence in Human Society (in Evolution and Ethics, and Other Essays (London, 1894), 202-218.)

Johnson, Steven, (2001) Emergence: The Connected Lives of Ants, Brains, Cities, and Software, New York: Penguin Press.

Kropotkin, Peter (1902) Mutual Aid: A Factor of Evolution (republicado em 1939, New York: Penguin Books) (http://www.calresco.org/texts/mutaid.htm)

Le Galès, Patrick, (2007) Las ciudades Europeas. Conflitos Sociales y Gobernanza, Madrid: DGUPR (do original, European Cities, Social Conflicts and Governance)

Neumann, John von; Morgenstern, Oskar, (1944) Theory of Games and Economic Behavior, Princeton, NJ: Princeton University Press.

Nowak, Martin A. (2006). 'Five Rules for the Evolution of Cooperation', Science, 8, December 2006: 15601563.

Ostrom, Elinor (1990) Governing the Commons: The Evolution of Institutions for Collective Action, Cambridge: Cambridge University Press.

Queirós, Margarida (2000) 'Utilitarismo ou equidade? Dilemas na política ambiental', Finisterra - Revista Portuguesa de Geografia, XXXV, 70: 103-114.

Rheingold, Howard (2002). Smart Mobs: The Next Social Revolution. USA: Basic Books.

Ruse, Michael (2002) O mistério de todos os mistérios, Lisboa: Ediçōes Quasi, (do original, Mystery of Mysteries, 1999).

Sachs, Jeffrey (2008) Common Wealth. Economics for a crowded planet, London: Penguin Books. 